\title{
Creative and Learning Processes using Game-Based Activities
}

\author{
Wilawan Inchamnan ${ }^{*}$ and Karuna Yampray
}

\author{
College of Creative Design and Entertainment Technology, Dhurakij Pundit University, Bangkok, Thailand
}

\begin{abstract}
This paper gains a better understanding of how gameplay activities facilitate the creative learning process, reviews learning objects as game elements that influence creativity and learning outcomes, and focuses on learning activity in terms of a series of actions, namely goals, action and interaction, and interpretation. The series should be an element of object learning through game elements, that are adapted from a collection of content items, practice items, and assessment within game tasks. The findings illustrate the relationship between the series of actions within classroom activities, show the significant impact of learning outcomes and the series of actions' learning, and facilitate creative learning processes. The paper proposes a method for understanding the relationships between the learning processes that players undertake during gameplay, and the components of the game that allow these processes to occur. This method was synthesized from the focus group by considering the relationships of their learning outcomes and creative processes within game activities. Previous research studied the creative potential in puzzle game play in the process. The pilot participants in the study adapted the process that was observed during the game "Online Gunz 2: The Second Duel", and were recorded their learning outcomes. The anticipated outcomes represented how video games foster learning processes and creative processes. The results illustrate a significant conceptual method as interrelationships between meaningful learning and creative potential within a game-based activities.
\end{abstract}

Keyword: Creative Process, Game-Based Activities, Learning Processes, Player Experience, Behavior and Verbalization Method, Goal Learning; Action Learning; Interpretation Learning.

\section{INTRODUCTION}

The present era is one of change, with significant consumption of media, digital and information. Consequently, the behavior of living and learning has changed. Standards for learning are now higher than they have ever been, and individuals need greater knowledge and skills to survive and succeed (DarlingHammond 2006). There has been significant growth in game-based learning research in the past two decades (Inchamnan et al. 2014). Game-based learning refers to the use of video games to support teaching and learning (Santanen et al. 2002). Playing game has a significant role to help people to learn in a joyful environment (Rigby \& Ryan 2011). A digital game involves role-play characters, clever and complex problems to be solved, compelling music and graphics (Taylor \& Drummond 2009), and includes knowledge and skills being learned influentially during the course of playing. Playing game has a crucial role to help people to learn to solve problems (Rigby \& Ryan 2011). The series of actions in game activities should be an element of learning objects, which is a digital resource that can be reused to mediate learning (Przybylski et al. 2012).

Digital simulations and games potentially play a significant role in facilitating exploration and creativity.

*Address of correspondence to this author at the College of Creative Design and Entertainment Technology, Dhurakij Pundit University, Bangkok, Thailand; Tel: +(66) 29547300 attn 333; Fax; + (66) 29548651;

E-mail: wilawan.inn@dpu.ac.th

JEL: C73, D83, O31.
While some existing studies demonstrate the effectiveness of games in facilitating creativity (Heafner 2004), few studies focus on the impacts of specific game elements (for example, goals, actions) on the creative problem solving processes that occur during gameplay (Inchamnan et al. 2014; Inchamnan et al. 2013). There are few studies on how to measure the outcomes of learning to facilitate creativity. Learning is an iterative process that involves the activity or process of gaining knowledge or skills by studying, practicing, being taught, experiencing something (Perrotta et al. 2013), or problem solving. Previous studies examined puzzle -based games with creative potential, whereas this study adopts the framework in (Inchamnan et al. 2014) to discover the relationships between the learning and creative processes. The paper focuses on games that have been specifically designed for educational purposes and facilitate problems solving skills as a learning object, and examines the impacts of game activities on facilitating creativity in terms of thinking. Creative thinking is an important aspect of problem solving and is a valuable skill to acquire. Owning to the limitations of time and budget, we tested only one game (MMORPG: Massive Multiplayer Online Role-Playing Game) to discover the conceptual model and that might be applied to other games.

This research may adjust to the creative process framework (MacLean et al. 2010) in terms of learning outcomes. The research questions are game activities that can influence the learning processes, and how creative processes can facilitate learning processes in role-play based game. The observed behavior and 
verbalization method design may contribute to verify ideas of safety systems in game environments, as well as to human learning.

The plan of the rest of the paper is as follows. Section 2 presents the related background. Section 3 discusses game-based activities and creative process assessment. Section 4 analyses a creative process and learning outcomes. Section 5 discusses creative and learning processes with game-based activities. Concluding comments are given in Section 6.

\section{RELATED BACKGROUND AND THEORY}

The related backgrounds aim to gain a better understanding of which gameplay activities facilitate learning outcomes. Gameplay activities examine the creative process through the creative potential method, and adapt from previous research in the creative potential of game design (Inchamnan et al. 2014). The primary focus is on creating learning objects and gamebased elements with a view to analyzing the extent to which elements promote meaningful learning and the learning objects for influencing learning outcomes, the learning process as a game task for influencing learning processes. The learning processes are measured by using, and assessing the interface between the player and the action taking place within the game environment.

\subsection{Learning Processes}

Learning processes are involved in setting, monitoring, and modifying the goals and objectives of the task (Nunan and Lamb 1996). Game play experiences that are active and provide intrinsic motivation have great potential to support learning processes (Paras and Bizzocchi 2005). Some researchers defined and intentionally integrated course learning objectives to: 1) help organize structured and enhance student learning; 2) improve communication with students and other instructors regarding important concepts and skills covered in a course; and 3) improve assessment practices (Taylor and Drummond 2009). This research addresses the learning objects as game elements through how the objects can organize learner's goals and motivation. Measuring this creative potential and learning processes involves assessing aspects of the human personality, and achieved through self-report measures using personality profiles, inventories, questionnaires, or checklists (Selby et al. 2005). The assessment uses the Player Experience of Need Satisfaction (PENS) survey for this purpose.
PENS measures the individual player experience by assessing the interface between the player and the action taking place within the game environment, and how the action and reaction between the player and the game satisfies specific psychological needs (Spearman 1930).

\subsection{Organize Learning Goals}

Learning goal orientation may facilitate the maintenance of adaptive motivation patterns. Many studies address the importance for students of developing ways of thinking that can help them to process information, plan student activities, monitor their attention, and sustain motivation for learning. Masters goals are salient and are adopted by students (Ames and Archer 1988). The goal is crucial for the motivation to learn. Organizing learning goals is crucial to educational improvement. In a game context, motivation can be defined as the set of game characteristics that prompt a player to realize specific actions and continue the game task until goal achievement (Sánchez et al. 2009). Setting a learning goal refers to the selection of a motivation strategy to fit the actual learning situation (Svinicki 2005). A design game for learning objects should be concerned with concepts of organized learning goals.

\subsection{Motivate to Learn}

Many studies address the ideas of using technology to motivate students to learn, such as social studies (Heafner 2004). Motivation refers to what a person will attempt, while ability is defined as what a person can achieve (Inchamnan et al. 2014), and can foster student engagement in their classroom or learning lesson. Motivational beliefs also refer to the student's opinion of the efficiency or effectiveness of learning and teaching methods (Boekaerts 2007), and makes learners believe in their skills. Such beliefs act as a frame of reference that guides students' thinking, feelings and actions in a subject area (Boekaerts 2007). Game play experiences that are active and provide intrinsic motivation have great potential to support learning processes (Paras et al. 2005). Importantly, the activity can also have a positive impact on learning, and intrinsic motivation (Amabile 1996).

\subsection{Meaningful Learning Experiences}

The project entitled The National Survey of Student Engagement (NSSE), studies meaningful learning as an essential engagement in class (Kuh 2001). 
Meaningful learning emphasizes students' acquisition of new information, and its linkages to previous experiences and knowledge in the formation of personal and unique understandings (Huang et al. 2011). Teachers should make tasks, and activities meaningful for students by referring to the intrinsic value of the task, and potential applications in other subject areas and outside school (Svinicki 2005). Meaningful learning experiences can design new models of meaningful activity in virtual worlds as preparation for meaningful activity in our post-industrial, technology-rich, real world (Shaffer et al. 2005), as game activities.

The researchers support the ideas by mentoring instructors who highlight evaluation procedures, give public feedback, frequently make social comparisons, and refer to individual abilities to create a competitive atmosphere, and elicit ego-oriented thoughts and feelings (Boekaerts 2002). Meaningful learning experiences influence the motivation to learn, while game elements can support a positive learning experience and encourage players (Inchamnan 2014). Game activities that energize players with a high degree of arousal have the potential to enhance creativity. Video games have been demonstrated to improve visual perception, processing and attention (MacLean 2010). Games may present a series of challenges, and can provide the incentive to engage in the act of gaining knowledge. The hypothesis of this paper focuses on learning processes encourages by meaningful learning experiences.

\subsection{Game Activities for Learning}

Games are engaging, can be effective, and have a place in learning (Van Eck 2006). Playing games have a significant role in helping people to learn (Paras 2005). Learning the rules of a game allows players to interact with game objects, and avoid an environment of frustration and confusion. This learning experience allows players greater freedom in terms of decisionmaking. The interactive experience with the game environment allows expressions of creativity and intentions (Sweetser and Johnson 2004). The guideline of game-based learning is to map the game activity components to the mechanisms identified (Inchamnan et al. 2014), and learning skills. Games with instructional activities that preserve the context (situated cognition) of the game (for example, the goals and character roles of the game in the classroom despite the games not covering instruction in all the learning areas) (Van Eck 2006). The following sub- sections (Figure 1) focus on in-game learner activity in terms of a series of actions, namely goals, action and interaction, and interpretation of learning. The series should be an element of the learning object.

\subsubsection{Goal Learning}

One of the factors that influence student learning is motivation. Teachers can affect student motivation in ways that either facilitate or impede learning (Svinicki 2005). Achievement goal orientation is a general motivation theory that refers to the fact that the type of goal toward which a person is working has a tremendous impact on how they pursue the goal. The most frequently mentioned value of learning goals has been that it helped students "know what I need to know" for a course. The learning goals are a contract between the teacher and students, so they can all know what is the foundation. A clear goal of learning and designing activities for a given grade, perhaps the best way is to make criteria clear and readily available to students so they can meet the standards without having to constantly ask about the requirements. If possible, give learners some choice in how the way they might learn. Ensure that the class includes clear goals that allow students to develop their own subgoals and problem-solving skills, and foster their learning (Inchamnan et al. 2014).

\subsubsection{Action and Interaction Learning}

A significant role in helping to learn (Paras 2005), for example, learning the rules of a game, allows players to interact with game objects and avoid an environment of frustration and confusion. Actions are meaningful subcomponents in the larger picture of the game, and answer the question: "What can the players do" (Schell 2014). Game play is fundamental for allowable actions and interactions of the player. The action learning plans the problem solution and what learners can do (actions) to improve their skills further, and the chances are good that they are interested in opportunities to practice these skills through their actions (Svinicki 2005). The guidelines below illustrate the concept of games for learning series:

- Create challenges in the class that require logical thinking, involvement and strategic planning (complexity in problem solving, planning, refining problem solutions)

- Implement challenges that develop at an appropriate pace and match a student's skill level (facilitate striving activity, environments that instill feeling autonomy); and 
- Implement rules that offer freedom of choice, where students have options about what actions to use to solve a problem in the class lesson (wide focus, object use and manipulation, planning) (Inchamnan et al. 2014).

\subsubsection{Interpretation Learning}

Interpretation is a process of evaluating learning progress. Interpretation learning refers to evaluation process learning, which can change current goals, involves a person's perception of the situation, the interpretation of that perception, and an eventual evaluation of those perceptions (Norman 1986). Individuals develop an ability to assess their achievement by perceiving outcomes and interpreting feedback (Malone 1981). They reflect on many experiences in games based on their interactions with the environment, and to understand how game-based learning should examine the elements of game play.

Game play involves players performing actions and assessing outcomes. It is through interpreting and reflecting upon feedback within a game that players refine their behavior. Interpretation of a game state stems from the visual representation that is the result of an application of the game rules within a given situation. In order to evaluate whether a game goal or sub-goal has been achieved, some kind of cognitive processing needs to occur (Norman 1986). Within game environments, interpretation learning allows patterns of errors to emerge. Reviewing guideline for the concept of games for interpretation within the game play's environment, and learning series (Inchamnan et al. 2014):

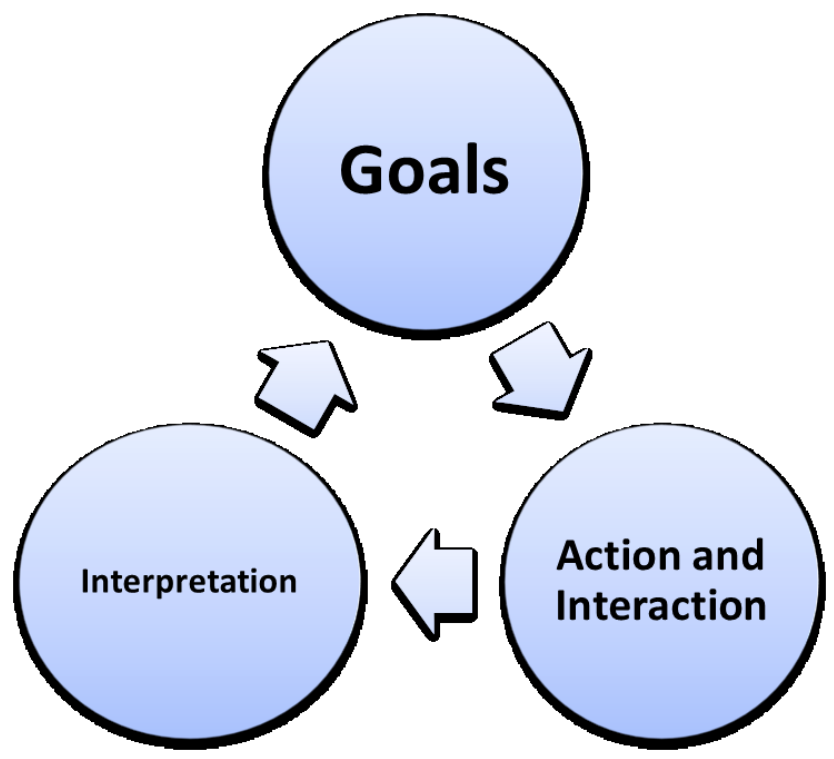

Figure 1: Series of Actions in Learning.
Manage student errors by allowing support for recovery from errors, and by ensuring that the impact is minimal (facilitate striving activity, environment that instills confidence); and

- Allow students to receive immediate and continuous feedback on their actions (environment that instills competence, understand what is required, clear pathways to complete lessons).

Interpretation includes players perceiving and interpreting feedback, as well as their evaluation of that feedback. This paper focuses on the relationship between learning objects and game-based elements that emphasize logical thinking and learning outcomes.

\subsubsection{Creative Learning Object}

Teaching and learning methodology involves one that delivers knowledge to learners within a classroom environment. Digital games within the multimedia learning environment may foster the learning process effectively and interestingly especially among young learners (Tan et al. 2007). What is important to facilitate the learning process in game-based learning? Game Object Model addressed by Amory provides a better guide as it combines both pedagogical elements and game development elements (Amory 2007). The model examines complex computer and video games that might provide a vehicle, based on appropriate theoretical concepts, to transform the educational landscape (Amory 2007). An appropriate game element should be developed based on some criteria that fulfill the requirements learning objects: mediate material learning; organize learning goals; motivate to learn; and improve assessment learning. Tan, P.-H., et al. (2007) points out the design framework for edutainment environment has two unique elements which are difficult to learn and psychological needs. It explains that educational game could be appropriate for children because the game could provide fun and play to fulfill the children's psychological needs and hence motivate them (Tan et al. 2007).

This review points out the series of actions: goals, action and interaction, and interpretation of learning. Goal learning addresses the learners to organize their goal. Goals can motivate people to learn. Learners can action their outcome of learning by using the assessment goal. The evaluating learning can change the current goal, involves a person's perception of the situation, the interpretation of that perception and an eventual evaluation of those perceptions. Game tasks 
can mediate material of learning and influence creativity. Creative learning object involves thinkers organizing learning goals, motivating to learn, and improving assessment learning.

Tan et al. (2007) note the design framework for edutainment environment has two unique elements that are difficult to learn, and psychological needs. It explains that educational games could be appropriate for children because the games could provide fun and play to fulfill the children's psychological needs, and hence to motivate them (Tan et al. 2007). This review point out the series of actions: goals, action and interaction, and interpretation of learning. Goal learning addresses learners to organize their goals, and can motivate individuals to learn. Learners can affect the outcomes of learning by using assessment goals. The evaluating learning can change the current goal, involves a person's perception of the situation, the interpretation of that perception, and an eventual evaluation of those perceptions. Game tasks can mediate material of learning, and influence creativity. Creative learning objects involve thinkers organizing learning goals, motivating to learn, and improving assessment learning.

\subsection{Creative Processes}

Creative processes support the use of creative thinking skills and include opportunities for play, exploration, reflection and focused engagement with ideas. A creative process is an internal process through which ideas are generated. Creative activity is the result of individuals being intrinsically motivated to interact and act in creative thinking (Inchamnan et al. 2014). Creativity in this paper concentrates on the creative individual deployed during learning activities.

\subsubsection{Measuring Creative Processes}

This paper initially observed fifteen students in the experiments. The students' grades during the study period were observed in order to evaluate logical skills (that is Mathematics and Programming subjects) and creative art skills (that is Animation Drawing subject). The principals of learning involved in the game-based learning were divided due to the assumption that video games can impact on overall academic achievements. The principles refer to the underlying assumptions and concepts. The majority of the studies examines the impact of video games on the student's motivation and their school records: programming, mathematics, and art subjects. Participants played the game Gun $Z$ 2: The Second Duel, between their online friends and
Robots (Bots). In the experiments, gameplay finished in 15 minutes approximately, and participants are needed to complete a player experience needs satisfaction (PENS) questionnaire (Przybylski et al., 2012), after playing.

The survey will address their meaningful experience in the learning process. Post-play assessment includes PENS variables containing sub-scales for in-game competence, autonomy, presence, and the intuition of the controls. The questionnaire employs a uniform 7point Likert scale, with anchors appropriate to each question. Specific sub-scales are described below (Rigby \& Ryan 2011):

- PENS: In game Competence. This scale measures participants' perception that the game provides competency;

- PENS: In game Autonomy. This scale assesses the degree to which participants felt free, and perceived opportunity to do activities that interest them;

- $\quad$ PENS: In game Presence. This scale measures the sense of immersion in the gaming environment. Three items considered are: physical presence, emotional presence and narrative presence;

- PENS: In game Intuitive Control (IC). This scale assesses the degree to which participants control their character's actions in the game environment;

- PENS: In game relatedness. This scale assesses the desire to connect with others in a way that feels authentic and supportive.

\subsubsection{Creative Potential Game Design Model}

The interactive experiences within the game environment allow players to express their creativity and intentions (Sweetser \& Johnson 2004). Research on creativity has resulted in multiple definitions, perspectives, and models. For example, creativity has been defined as a group of at least four components: creative process, creative product, creative person, and creative situation (Huang et al. 2011). It has also been grouped by using four definitions: product, person, press (the "press" of the environment), and process (Taylor 2009). Our research concentrates on the creative process, specifically, the thinking processes employed during creative activity. The creative process is the result of sustained and complex mental effort 
over time (Svinicki 2005), and consists of a step-bystep sequence of mental activities.

In order to identify the potential of games to engage players in creative processes, criteria related to activity undertaken need to be clearly understood. While we understand that games have great potential to support creative processes (Santanen, Briggs \& Devreede 2002), it is not clear yet how we design for creative activity. Creative ideas arise from the novel combination of ideas (Spearman 1930), that creativity involves a process of convergent and divergent thinking (Ames \& Archer 1988), and that critical thinking plays an important role (Inchamnan et al. 2014). In order to develop interactive experiences that incorporate these variables, and educative processes, this paper needs a clearer understanding as to how different game elements are combined to produce creative potential.

In previous studies some games such as Portal 2 activities found evidence to support the ideas (Inchamnan et al. 2014; Inchamnan et al. 2013). Curious answers are which other game activities can influence the learning processes, and how the game elements can facilitate learning skills in terms of creative processes. This study uses Gun $Z$ 2: The Second Duel online, which is a free game, and where the participants have not played before. Massive Multiplayer Online Role-Playing Game (MMORPG) is also quite famous for Thai gamers. The game mechanics may support more general ideas in game tasks.

This research applies the creative potential game design model that can be described, based on two previous studies (Inchamnan et al. 2014; Inchamnan et al. 2013). In the first study, the experiment was conducted to measure the creative processes that occur during the gameplay (Inchamnan et al. 2014). The conceptual method that is employed to assess creativity examines the extent to which factors identified as important in the creative processes - task motivation, domain-relevant skills, and creativityrelevant skills - are presented within gaming experiences. The study involved participants being observed while playing the three selected puzzle games: Portal 2, Braid, and I-Fluid. Portal 2 was played from the first-person perspective, and involves solving puzzles via the placement of portals within the environment: Braid is a platform-styled game that involves solving puzzles by manipulating time features.
I-Fluid is a game where players can control a drop of water, and attempt to solve physics-based puzzles. In order to examine the creative process, participants were video recorded while playing the games, and a video-coding scheme was used to capture the type and frequency of the observable behavior and participant verbalization (Inchamnan et al. 2014).

In the second study (Inchamnan et al. 2014; Inchamnan et al. 2013), the experiment was conducted to examine specific elements of the three games used in the first study to determine which of these elements are important in fostering creativity. A heuristic checklist forms the basis of the study. Experts used the items in this checklist to analyze each game. The list items are structured into the categories identified as the key components of moment-to-moment gameplay. The three categories - identify goals, perform meaningful action and interpret outcome - map to a model of interaction that is based on cognitive processing. This model provides the important link between specific elements of games and creative problem-solving activities.

\section{GAME-BASED ACTIVITIES AND CREATIVE PROCESSES ASSESSMENT}

This assessment focuses on game-based activities in terms of the series of actions: goals, action and interaction, and interpretation of creative learning outcomes. The proposed methodology is involved in class activities by using learning objects, which are the series of actions, namely: Goal for learning; Action in class; and interpretation learning. The questionnaire asks the three questions: "What is the objective of learning today?", "What are you doing today?", and "What do you know in class today?". The lecturer rates their skill for each activity by using a seven-point Likert scale ('Strongly agree' to 'strongly disagree'). The action class is measured by using the learners' midterm score. The second stage involves the determination of relationships of creativity and learning objects. The objective of this stage is to investigate and establish related elements that support creative performance and learning outcomes. In terms of creativity, the instrument used for data collection consists of two series of blank pictures. The participants fill a creative picture by themselves, then two experts use a seven-point Likert scale ('Strongly agree' to 'strongly disagree') for ranking creativity. Figure 2 shows an example of the outcomes between $A$ and $B, C$ and $D$. 


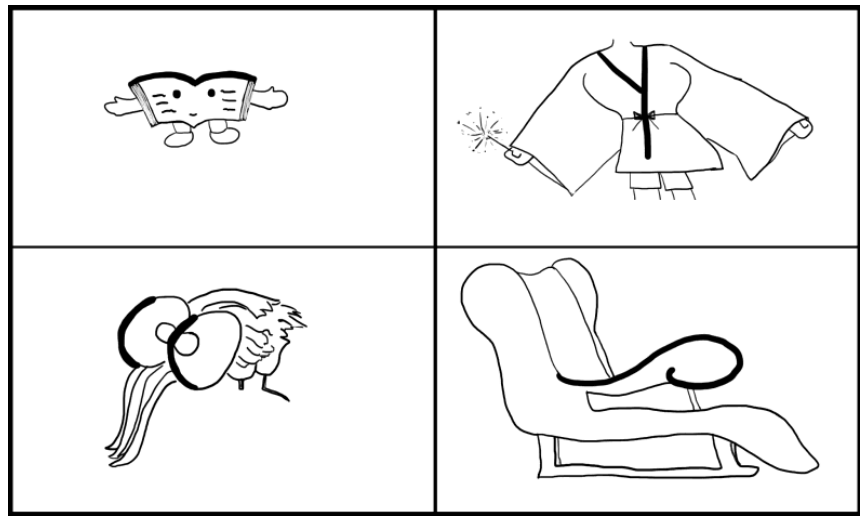

A

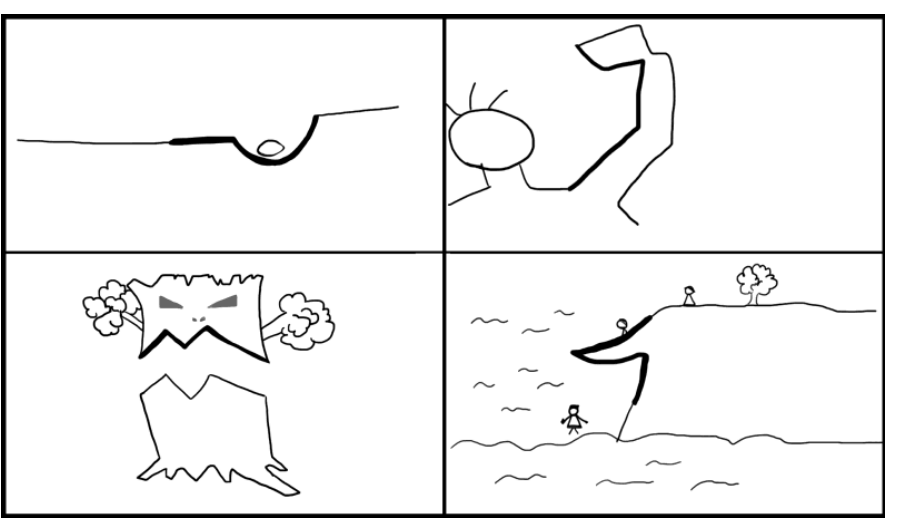

C

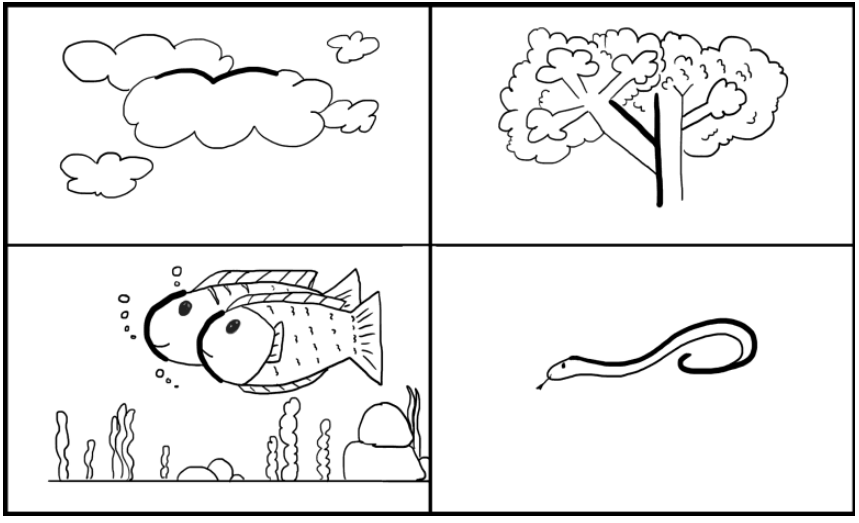

B

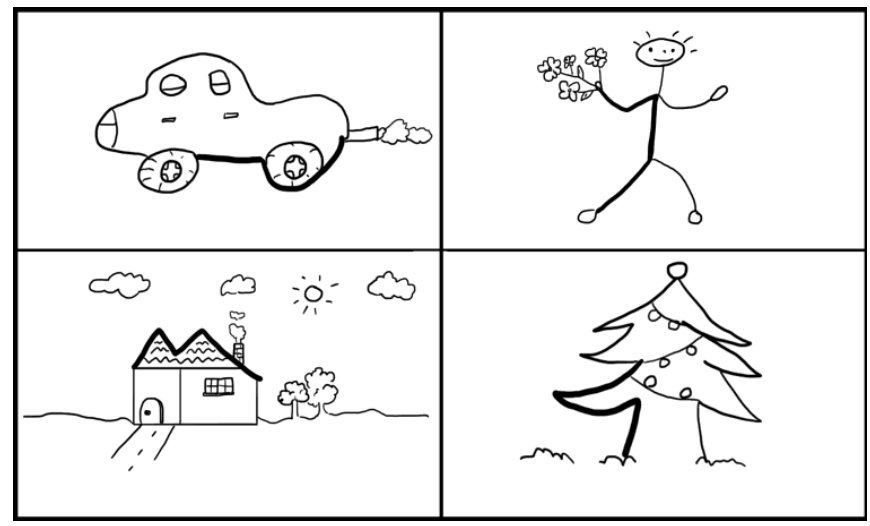

D

Figure 2: Creativity Pictures.

\subsection{Participants}

Thirty-four pilot participants were involved in the study; four female and thirty males. They were first and third years in students Interactive Design and Game Development, Information Technology Faculty student, with only a few female enrolled in the course. Their ages were found 17 to 24 . Most participants have played games for more than 7 years, and have enough game experience to conduct the test. In order to examine the learning outcomes, all participants were evaluated from class activities to the series of learning: goal, action, and interpretation. It examines the impact of these activities on player experience by evaluating school record outcomes during their study in the Game Design (GT201) and Texturing 3D (GT319) subjects.

\subsection{Relationships between the Series of Actions during Learning}

Table 1 shows the details of paired differences, the findings are significant $(\alpha<.05)$ For the relationships between interpretation and action in class, participants have more learning outcomes (Actions in class) when they know the goal of learning and interpret their learning (Interpretation).

\subsection{Creativity and Learning Outcome: Impact of Learning Outcomes and Series of Learning}

The results in Table 2 are significant $(\alpha<.05)$ for the relationships between game experience and creativity within classroom activities. Participants have creative skills when they have more experience in

Table 1: Series of Learning Test (Paired Samples T-Test)

\begin{tabular}{|c|c|c|c|}
\hline Pair & $\mathbf{t}$ & Df. & $\begin{array}{l}95 \% \text { Confidence Interval of the } \\
\text { Difference Significant. (2-tailed) }\end{array}$ \\
\hline $\begin{array}{l}\text { Interpretation Learning and Action and } \\
\text { Interaction in class (Midterm score) }\end{array}$ & -20.358 & 33 & .000 \\
\hline $\begin{array}{c}\text { Action and Interaction in class (Midterm score) } \\
\text { - Goal for Learning }\end{array}$ & 6.305 & 33 & .000 \\
\hline
\end{tabular}


Table 2: Series of Learning and Creativity (Paired Samples T-Test)

\begin{tabular}{|c|c|c|c|}
\hline Pair & $t$ & Df. & $\begin{array}{l}\text { 95\% Confidence Interval of the } \\
\text { Difference Significant. (2-tailed) }\end{array}$ \\
\hline Game Experience - Creativity & 2.375 & 13 & .034 \\
\hline Creativity - Goal for Learning & -.168 & 13 & .869 \\
\hline Goal for Learning - Game Experience & -2.027 & 13 & .064 \\
\hline Creativity - GPA & 3.581 & 13 & .003 \\
\hline
\end{tabular}

game activities. The result also shows the relationships between learning outcome (GPA) and creativity. Clearly, participants have better learning outcomes (GPA) when they have more creative skills. The summary of this assessment finds the learning objects influence learning outcomes. The findings illustrate the relationship between the series of actions within classroom activities, and show significant impacts of learning outcomes and the series of actions learning. The findings refer to the learning outcomes as influenced by gameplay experience and creative skills. Significantly, game-based elements refer to create learning objects. The single goal in game tasks should be a model for learning objects design.

\section{CREATIVE PROCESSES AND LEARNING OUTCOMES}

In order to examine the creative process, all participants were video recorded while playing, the game and a video coding scheme was then used to capture the type and frequency of observed behavior and verbalization (Inchamnan et al. 2013). Behavioral assessment provides a method for analysis of the creative processes and has been used previously to measure creativity. The method examines the reliability of our adaptation of this measure of the creative process for use within the computer game context. Behavior in game tasks such as set breaking, task pace and enjoyment, are identified as important elements of task motivation. The measures identified as predictors of creativity in terms of domain-relevant skills, for use in the context of computer game play, are assuredness, difficulty and exhibited uncertainty. Creativity-relevant skills are measured through the specific process factors of concrete focus, concept identification, wide focus and striving (Inchamnan et al. 2014; Inchamnan et al. 2013).

Fifteen pilot participants consisting of one female and fourteen males are senior-level students in the Interactive Design and Game Development department, Faculty of Information Technology,
Dhurakij Pundit University, Thailand, with ages are between 21 and 24. Most participants have a gaming experience of more than 7 years, which is enough to conduct the test. The participants were tested by playing game GunZ 2. In order to ensure that all variables contributed equally, all frequency tally scores were standardized (Przybylski et al. 2012). The observed behavior and verbalization examines the impact of these activities on player experience by evaluating school record outcomes during their study of almost four years.

\subsection{Task Motivation Skills and Learning Process}

Task motivation is assessed through an examination of the social-environmental influences of motivation. These are intrinsic and extrinsic factors that support autonomy, competence, control, and task involvement (Amabile 1996).

The significant mean differences of PENS scores across the creative components, as shown in Table $\mathbf{3}$, shows that players felt competent during involvement in the game. The finding identifies significant player experience of playing games at $\alpha<.05$, that impacted with involvement (Task motivation) within the game play. The task motivation skill encourages learning activity through the degree to which players have experience in gameplay (Involvement and Year of Game Experience). The programming results assess the degree to which a player has logical thinking about learning. These results showed significant player learning at $\alpha<.05$, that was significant with task motivation skills within the game play. The learning outcomes show the relationship with player's feeling competent.

\subsection{Domain-Relevant Skills and Players' Experiences}

The findings identifies (Table 4) that creative potential, in terms of domain-relevant skills required, is self-initiated, backtracked by using intentional moves to previous locations, or by revisiting a particular game 
Table 3: Significant Mean Differences of Task Motivation Skills and Learning Outcomes Across PENS

\begin{tabular}{|c|c|c|c|}
\hline Source & Variable & $\mathbf{F}$ & Significant \\
\hline T1: Creative Game Tasks and PENS & Involvement and Competence & 7.698 & .018 \\
\hline \multirow{2}{*}{ T2: Creative Game Tasks and skills } & Involvement and Year of Game Experience & 8.103 & .004 \\
\hline & Exploration and Programming & 7.784 & .004 \\
\hline \multirow{2}{*}{$\begin{array}{l}\text { T3: Learning Outcome and Creative } \\
\text { game tasks }\end{array}$} & Programming and Pace & 4.104 & .032 \\
\hline & Programming and Planning & 5.649 & .012 \\
\hline T4: Learning Outcome and PENS & GPA and Competence & 8.361 & .015 \\
\hline
\end{tabular}

Table 4: Significant Mean Differences of Domain-Relevant Skills and Players' Experiences

\begin{tabular}{|c|c|c|c|}
\hline Source & Variable & $\mathbf{F}$ & Significant \\
\hline D1: Creative Game Tasks and skills & Exhibited uncertainly and Year of Game Experience & 5.721 & .013 \\
\hline
\end{tabular}

task/challenge within the gameplay activity (Exhibited uncertainty game activity). The domain-relevant skill encourages learning activity through the degree to which a player has experience in gameplay (Years of Game Experience).

\subsection{Creative-Relevant Skills and Learning Process}

The significant mean differences of PENS scores across the creative components, as shown in Table $\mathbf{5}$, show that players felt free, and perceived opportunities to do activities that interest them. The intuitive control scale aims to assess the degree that participants control their character's actions in the game environment. The findings show significant differences in learning outcomes through participants' Grade Point Average (GPA) within the players' feeling intuitive control during playing games. These findings refer to game activities can facilitate individual's learning outcomes by using the creative process skills. The results show the relationship between players' feeling, intuitive control, and concept identification and striving.

In game relatedness, the scale assesses the desire to connect to others in a manner that feels authentic and supportive. These results show significant player experience $(\alpha<.05)$, that is significant to the concept identification within the game play.

Player's experiences impact on creative-relevant skills (Concept identification). Logical thinking skills as programming and math also influence skills. These results show significance at $\alpha<.05$ of the relationships between Art subject and creative-relevant skills as concept identification within game play activities. These findings show that game activities encourage participants to learn more effectively.

Table 5: Significant Mean Differences in Creative-Relevant Skills and Learning Outcomes Across PENS

\begin{tabular}{|c|c|c|c|}
\hline Source & Variable & F & \multirow{2}{*}{ Significant } \\
\hline \hline \multirow{2}{*}{ C1: Learning outcome and PENS } & GPA and Intuitive Control & 5.977 & .050 \\
\hline \multirow{2}{*}{ C2: Creative Game Tasks and PENS } & Striving and Autonomy & 5.301 & .040 \\
\cline { 2 - 4 } & Concept identification and Intuitive Control & 6.305 & .045 \\
\cline { 2 - 4 } & Striving and Intuitive Control & 6.587 & .042 \\
\cline { 2 - 4 } & Concept identification and Relatedness & 5.003 & .025 \\
\cline { 2 - 4 } C3: Creative Game Tasks and skills & Concept identification and Year of Game Experience & 14.707 & .000 \\
\cline { 2 - 4 } & Wide focus and Math & 6.424 & .008 \\
\cline { 2 - 4 } & Concept identification and Programming & 9.068 & .003 \\
\hline \multirow{2}{*}{ C4: Learning Outcome and Creative game tasks } & Art and Concept Identification & 4.406 & .044 \\
\hline
\end{tabular}




\subsection{A Method for Measuring the Learning Processes and Creative Processes: Using Online Game Based Activities}

The method presented in Figure $\mathbf{3}$ is used to assist game developers to produce games that facilitate learning and creative processes. This paper examines a method for measuring learning and creative processes through online game activities. From the results, learning outcomes have to be mapped to the mechanisms of learning that are identified for facilitating creative potential. The results of task motivation activities showed that the game challenges effectively allowed to the cognitive and logical thinking, and strategic planning (T3). In this paper, task motivation factors in game activities (T1, T2, T3) are linked to learning processes through player's feeling competence, and the learning outcome as GPA have a relationship with the player's feeling competence (T4).

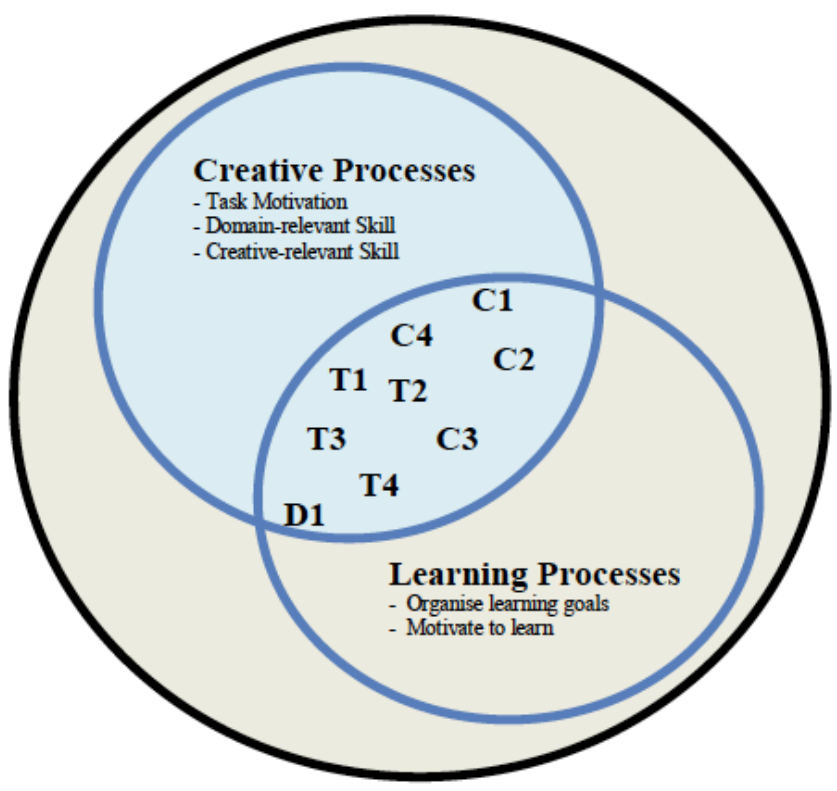

\section{Game Activites}

Figure 3: Measuring the Learning Processes and Creative Processes: Using Online Game Based Activities.

In identifying domain-relevant process (D1 in Table 4), ideal conditions for creativity were achieved within self-initiated backtracks by using intentional moves to previous locations, or revisits to a particular game task/challenge (Exhibited uncertainly and Year of Game Experience).

From a creativity-relevant skills perspective, game activities included providing greater opportunities for players to strive while engaging in game play. This could be achieved by allowing an activity that involves learning mechanisms (Striving and Autonomy; Striving and Intuitive Control). The results referred to game activity experiences as the intuitive control that affects learning outcomes $(\mathrm{C} 1, \mathrm{C} 3, \mathrm{C} 4)$. Learning outcomes could also be achieved by allowing an activity that was future oriented. The creative-relevant skills encouraged the learning activities through the degree players have logical thoughts of learning (C2)

Figure 3 represents the knowledge of how to measure creative and learning processes. The figure illustrates a conceptual method as the interrelationships between meaningful learning and creative potential that were applied from the online game (Online Gunz 2: The Second Duel).

\section{CREATIVE AND LEARNING PROCESSES WITH GAME-BASED ACTIVITIES}

The findings show that game activities can influence the learning and creative processes. The method was tested by using the observed behavior and verbalization method design that may contribute to verification ideas of safety systems in game environments, as well as to human learning. In terms of learning experiences, creative-relevant skills can influence good GPA and math skills. The model identifies a relationship between task motivation and involvement, pace, exploration and planning. Task motivation and learning experiences encourage and programming skills. The creative potential, in terms of domain-relevant skills required, is self-initiated and backtracked by using intentional moves to previous locations, or by revisiting a particular game task/challenge within the game play activity (Exhibited uncertainty game activity). The results from this research show that game activities can influence creative processes (Figure 4), and creative processes have a relationship with learning processes.

\section{CONCLUSION}

This paper demonstrated that existing measures and techniques can be effectively adapted to assess the creative processes occurring in game play experiences. Creativity can be measured by examining the domain-relevant and creativity-relevant skills, as well as task motivation during game play. The learning processes can be measured by addressing a learning outcome and the Player Experience of Need Satisfaction.

As a result, this understanding can be applied to create a general method for designing new learning 


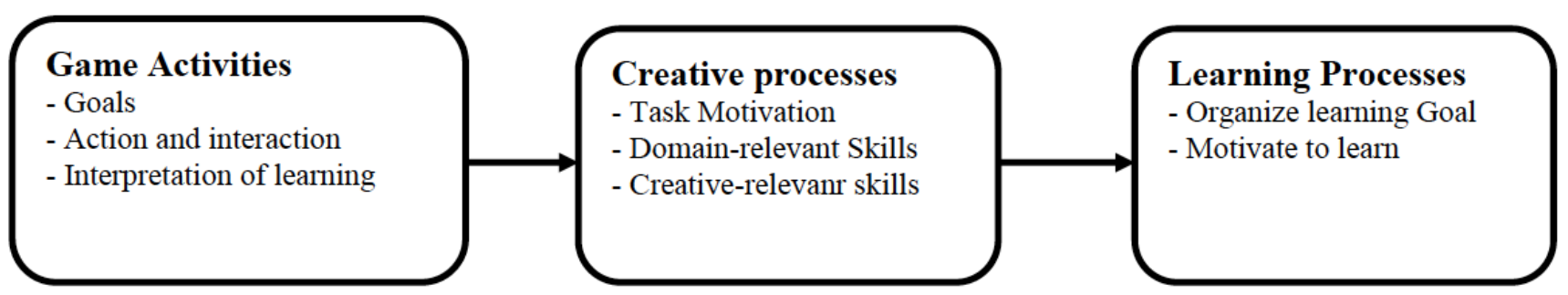

Figure 4: Relationship between Creative and Learning Processes with Game-Based Activities.

experiences. The finding significantly illustrates a method for measuring the creative processes and learning processes through game-based activities. The method can identify crucial characteristics of the creative process that emerge during the process of playing games and can identify mapping elements of games to the components of the creative process. The game activities can influence the meaningful experience by measuring a factor of how learners organize their goals and how they act during the motivation to learn.

\section{ACKNOWLEDGEMENT}

The authors wish to thank Chia-Lin Chang and Michael McAleer for helpful comments and suggestions.

\section{REFERENCES}

Amabile, T.M., 1996. Creativity in Context. Boulder, Colorado, Westview Press Inc.

Ames, C. and J. Archer, 1988. Achievement goals in the classroom: Students' learning strategies and motivation processes. Journal of educational psychology, $80(3):$ p. 260 https://doi.org/10.1037/0022-0663.80.3.260

Amory, A., 2007. Game object model version II: a theoretical framework for educational game development. Educational Technology Research and Development, 55(1): p. 51-77. https://doi.org/10.1007/s11423-006-9001-x

Boekaerts, M., 2002. Motivation To Learn. Educational Practices Series.

Darling-Hammond, L., 2006. Constructing 21st-century teacher education. Journal of teacher education, 57(3): p. 300-314. https://doi.org/10.1177/0022487105285962

Heafner, T., 2004. Using technology to motivate students to learn social studies. Contemporary Issues in Technology and Teacher Education, 4(1): p. 42-53.

Huang, Y.-M., et al., 2011. The design and implementation of a meaningful learning-based evaluation method for ubiquitous learning. Computers \& Education, 57(4): p. 2291-2302. https://doi.org/10.1016/j.compedu.2011.05.023

Inchamnan, W., P. Wyeth, and D. Johnson, 2014. Design for Creative Activity: A Framework for Analyzing the Creative Potential of Computer Games, in Entertainment ComputingICEC 2014, Springer. p. 19-26. https://doi.org/10.1007/978-3-662-45212-7_3

Inchamnan W., W.P., Johnson D., 2013. Behavioural Creative Components Analysis of Puzzle Gameplay. Proceeding 5th
International IEEE Games Innovation Conference (IGIC), Vancouver British Columbia, Canada.

Kuh, G.D., 2001. National Survey of Student Engagement: The College Student Report: NSSE Technical and Norms Report: Indiana University Center for Postsecondary Research and Planning.

MacLean, K.A., et al., 2010. Intensive meditation training improves perceptual discrimination and sustained attention. Psychological science, 21(6): p. 829-839. https://doi.org/10.1177/0956797610371339

Malone, T.W., 1981. Toward a theory of intrinsically motivating instruction*. Cognitive science, 5(4): p. 333-369. https://doi.org/10.1207/s15516709cog0504 2

Norman, D.A. and S.W.,1986. Draper, User centered system design. Hillsdale, NJ.

Nunan, D. and C. Lamb, 1996. The self-directed teacher: Managing the learning process: Cambridge University Press.

Paras, B. and J. Bizzocchi, 2005. Game, motivation, and effective learning: An integrated model for educational game design.

Paras, B., 2005. Game, motivation, and effective learning: An integrated model for educational game design.

Perrotta, C., et al., 2013. Game-based learning: latest evidence and future directions: NFER Slough.

Przybylski, A.K., et al., 2012. The Ideal Self at Play The Appeal of Video Games That Let You Be All You Can Be. Psychological science, 23(1): p. 69-76. https://doi.org/10.1177/0956797611418676

Rigby, S., \& Ryan, R., 2011. Glued to Games: How Video Games Draw Us in and Hold Us Spellbound: Praeger Publishers.

Sánchez, J.L.G., N.P. Zea, and F.L., 2009. Gutiérrez, From usability to playability: Introduction to player-centred video game development process, in Human Centered Design, Springer. p. $65-74$.

Santanen, E.L., R.O. Briggs, and G.-J. de Devreede, 2002. Toward an understanding of creative solution generation. in System Sciences, 2002. HICSS. Proceedings of the 35th Annual Hawaii International Conference on. IEEE.

Schell, J., 2014. The Art of Game Design: A book of lenses: CRC Press. https://doi.org/10.1201/b17723

Selby, E. C., Shaw, E. J., \& Houtz, J. C., 2005. The creative personality. Gifted Child Quarterly, 49(4), 300-314 https://doi.org/10.1177/001698620504900404

Shaffer, D.W., et al., 2005. Video Games and the Future of Learning. WCER Working Paper No. 2005-4. Wisconsin Center for Education Research (NJ1).

Spearman, C.E., 1930. Creative mind. D. Appleton and company.

Svinicki, M., 2005. Student goal orientation, motivation, and learning. Idea Paper No. 41. Manhattan, KS: Center for Faculty Evaluation and Development in Higher Education, Kansas State University. 
Sweetser, P., \& Johnson, D., 2004. Player-centered game environments: Assessing player opinions, experiences, and issues. Entertainment Computing-ICEC 2004, 305-336. https://doi.org/10.1007/978-3-540-28643-1 40

Tan, P.-H., et al., 2007. Adaptive digital game-based learning framework. Proceedings of the 2nd international conference on Digital interactive media in entertainment and arts, ACM. https://doi.org/10.1145/1306813.1306844
Taylor, S. and T. Drummond, 2009. Multiple Target Localisation at over 100 FPS. in BMVC.

Van Eck, R., 2006. Digital game-based learning: It's not just the digital natives who are restless. EDUCAUSE review, 41(2): $p$ 16.

Received on 16-02-2017

Accepted on 13-05-2017

Published on 09-06-2017

DOI: https://doi.org/10.6000/1929-7092.2017.06.37

(C) 2017 Inchamnan and Yampray; Licensee Lifescience Global.

This is an open access article licensed under the terms of the Creative Commons Attribution Non-Commercial License (http://creativecommons.org/licenses/by-nc/3.0/) which permits unrestricted, non-commercial use, distribution and reproduction in any medium, provided the work is properly cited. 